\title{
A biomechanical study of plate versus intramedullary devices for midshaft clavicle fixation
}

\author{
S Raymond Golish, Jason A Oliviero, Eric I Francke and Mark D Miller*
}

Address: Department of Orthopaedic Surgery, University of Virginia Health System, Charlottesville, Virginia, USA

Email: S Raymond Golish - sg3vu@virginia.edu; Jason A Oliviero - jao4x@virginia.edu; Eric I Francke - eif2c@virginia.edu;

Mark D Miller* - mdm3p@virginia.edu

* Corresponding author

Published: 16 July 2008

Journal of Orthopaedic Surgery and Research 2008, 3:28 doi:10.1186/1749-799X-3-28

This article is available from: http://www.josr-online.com/content/3/I/28

(c) 2008 Golish et al; licensee BioMed Central Ltd.

This is an Open Access article distributed under the terms of the Creative Commons Attribution License (http://creativecommons.org/licenses/by/2.0), which permits unrestricted use, distribution, and reproduction in any medium, provided the original work is properly cited.
Received: 17 September 2007

Accepted: 16 July 2008

\begin{abstract}
Background: Non-operative management of midshaft clavicle fractures is standard; however, surgical management is increasing. The purpose of this study is to compare the biomechanical performance of plate versus intramedullary fixation in cyclic bending for matched pairs of cadaveric clavicles. We hypothesized that the biomechanical properties are similar.

Methods: Eight sets of matched clavicles with vertical, midshaft osteotomies were prepared from fresh, frozen cadavers. A $3.5 \mathrm{~mm}$ dynamic compression plate or a 3.8 or $4.5 \mathrm{~mm}$ intramedullary device were used for fixation. Clavicles were loaded in a four-point bend at 6 different loads for 3000 cycles at I Hz starting with $180 \mathrm{~N}$ and increasing by $180 \mathrm{~N}$ with sampling at $2 \mathrm{~Hz}$. Failure was defined as $10 \mathrm{~mm}$ of displacement or catastrophic construct failure prior to $10 \mathrm{~mm}$ of displacement.

Results: Between constructs, there was a significant difference with large effect size in displacement at fixed loads of I80 N ( $P=0.001$; Cohen's $d=1.85), 360 \mathrm{~N}(P=0.033$; Cohen's $d=$ I.39), $540 \mathrm{~N}(P=0.003$; Cohen's $d=0.73)$ and $720 \mathrm{~N}(P=0.018$; Cohen's $d=0.72)$. There was a significant difference with large effect size in load at fixed displacements of $5 \mathrm{~mm}(P=0.00 \mathrm{I}$; Cohen's $d=1.49), 7.5 \mathrm{~mm}(P=0.0 \mathrm{I}$; Cohen's $d=1.06)$, and $10 \mathrm{~mm}(P=0.026$; Cohen's $d=0.84)$.

Conclusion: Plate constructs are superior in showing less displacement at fixed loads and greater loads at fixed displacements over a broad range of loads and displacements with cyclic four-point bending. The clinical relevance is that plate fixation may provide a stronger construct for early rehabilitation protocols that focus on repetitive movements in the early pre-operative period.
\end{abstract}

\section{Background}

Clavicle fractures comprise $5-10 \%$ of all skeletal fractures, and $80 \%$ of these occur in the middle-third [1]. These fractures result from a blow to the shoulder causing axial loading [2]. The standard of care is closed treatment with sling and swathe; however, recent studies have found higher rates of delayed union, nonunion, shoulder pain, and shoulder weakness with non-operative care [3]. Risk factors for poor outcome with non-operative treatment include shortening, initial displacement, fracture comminution, and age. The indications for surgery include the need for earlier functional mobilization in the patient with an isolated injury [4] in addition to open fractures and the polytraumatized patient. 
For operative treatment, open reduction and internal fixation with a $3.5 \mathrm{~mm}$ dynamic compression plate is the standard; however, intramedullary fixation is a less invasive alternative. A retrospective clinical study by Wu et al. compared plate to IM fixation for aseptic nonunions [5]. A biomechanical study by Proubasta et al. compared a 6hole $3.5 \mathrm{~mm}$ dynamic compression plate to a $4.5 \mathrm{~mm}$ intramedullary Herbert screw [6].

Clinically, cyclic bending is a likely model of construct failure, especially in the setting of early functional mobilization. Loosening at the bone-implant interface, fatigue failure, and broken hardware are clinical anecdotes shared by surgeons caring for patients with these injuries. No biomechanical study has compared plate to intramedullary fixation in cyclic bending. The purpose of this study is to compare plate fixation versus intramedullary fixation in cyclically loaded clavicles in a four-point bend with sequentially increasing loads. We hypothesized that the biomechanical properties are similar.

\section{Methods}

Eight sets of paired clavicles were obtained from 8 fresh, frozen cadavers. There were 5 male and 3 female specimens in the age range 37 to 68 years. Vertical osteotomies were made at the midpoint using an oscillating saw. A single clavicle from each matched pair set was randomly assigned to either the intramedullary fixation technique or the plating technique, and the contralateral clavicle was assigned to the other fixation technique.

Seven-hole, $3.5 \mathrm{~mm}$ titanium dynamic compression plates (ACE/Depuy, Warsaw, IN, USA) were contoured to the superior surface of reduced clavicles. The plate size was chosen to be the largest width that would contour smoothly to all cadavers samples without hardware prominence beyond the cortical borders. $\mathrm{AO}$ technique was used to place $3.5 \mathrm{~mm}$ cortical, fully threaded titanium screws; holes were drilled, tapped, and measured prior to screw selection. Six cortices of fixation were acquired on either side of the osteotomy, after positioning the middle hole of the plate over the osteotomy site to balance three holes evenly on either side. The Rockwood Pin (Depuy, Warsaw, IN, USA) was used as the intramedullary device to fix the osteomized clavicles. Using the technique recommended by the implant manufacturer, clavicles were repaired using either a $3.8 \mathrm{~mm}$ pin or a $4.5 \mathrm{~mm}$ pin depending on bone diameter. An attempt to insert a 4.5 $\mathrm{mm}$ pin was made, but if the pin proved too large to pass without binding or fracture, a $3.8 \mathrm{~mm}$ pin was passed. Five pins of $4.5 \mathrm{~mm}$ width and three pins of $3.8 \mathrm{~mm}$ width were used.

A custom jig consisting of 2 superior inner arms and 2 inferior outer arms was constructed to load clavicles in a four-point bend. Figure 1 is a photograph of the jig loaded with a clavicle for testing. The clavicles and arms were optimally positioned such that the osteotomy site was at the midpoint between both the inner and outer arms. Clavicles were placed with the superior surface contacting the outer arms and the inferior surface contacting the inner arms, loading the superior surface of the clavicle in tension. In order to stabilize this position during loading, two $0.157 \mathrm{~mm}$ K-wires were placed thru the jig and the clavicle's acromial end.

The MTS-Bionix (Materials Testing Systems, Minneapolis, MN, USA) servohydraulic testing machine with a $454 \mathrm{~kg}$ load cell was used to load the clavicles while a digital extensometer measured displacement. The clavicles were loaded for 3000 cycles at a frequency of $1 \mathrm{~Hz}$ starting with a force of $180 \mathrm{~N}$. The loading cycles of 3000 repeats were incrementally increased by $180 \mathrm{~N}$ such that the clavicles were tested at $180 \mathrm{~N}, 360 \mathrm{~N}, 540 \mathrm{~N}, 720 \mathrm{~N}, 900 \mathrm{~N}, 1080 \mathrm{~N}$ loads. The extensometer measured the peak and valley of each load cycle with a sampling rate of $2 \mathrm{~Hz}$. Testing was stopped after displacement of greater than or equal to 10 $\mathrm{mm}$ occurred, after catastrophic failure of the construct at the bone-implant interface, or at the completion of the $1080 \mathrm{~N}$ loading cycle. Data analysis was performed with SPSS 12.0 (SPSS Inc., Chicago, IL, USA) using paired t-

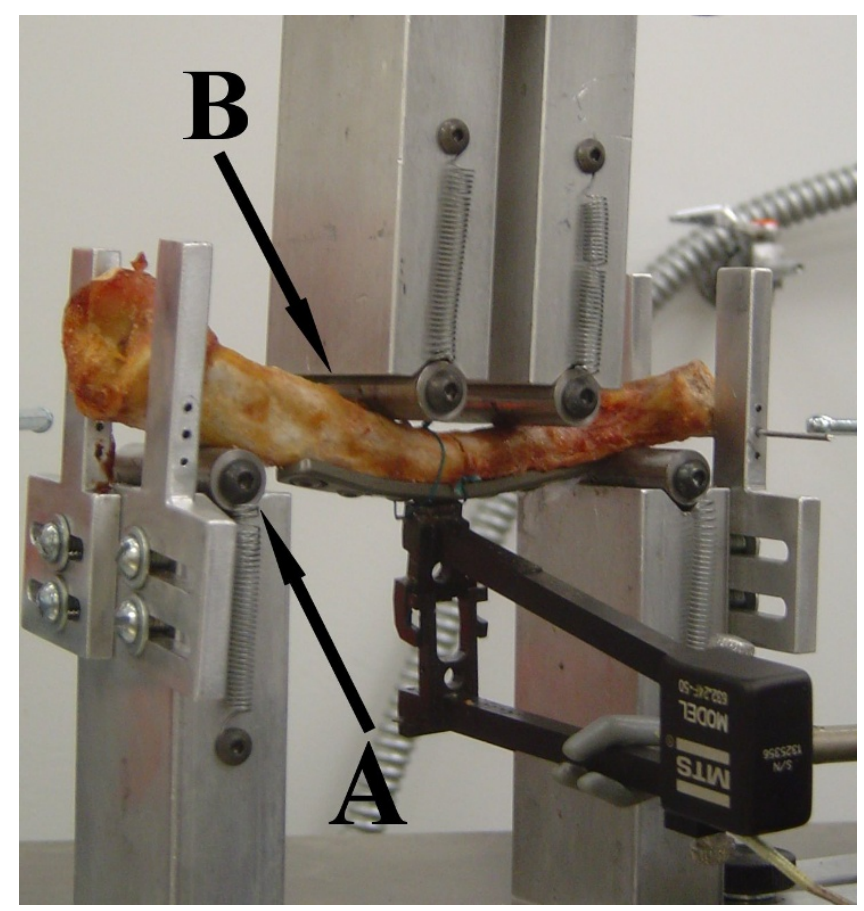

Figure I

Photograph of clavicle loaded in jig for testing by cyclic loading in a four-point bend. Label $A$ denotes the outer arm. Label B denotes the inner arm. 
tests, Wilcoxon signed-rank tests, chi-squared tests, and Bonferroni-Sidak multitest correction. An alpha value (type I error rate) of 0.05 was considered significant. Power analysis was performed with a beta value (type II error rate) of 0.20 in order to choose the sample size of 8 matched clavicle pairs as detailed in the results section.

\section{Results}

Eight matched pairs of clavicles ranged in length from 147 $\mathrm{mm}$ to $175 \mathrm{~mm}$ and ranged in diameter from $11 \mathrm{~mm}$ to $16 \mathrm{~mm}$. The diameter was measured at the widest point in the middle one-third of the bone. Table 1 summarizes the clavicle and test characteristics. Between matched pairs of clavicles, there was no significant difference in clavicle length $(P=0.99)$, diameter $(P=0.35)$, inner arm placement $(P=0.70)$ or outer arm placement $(P=0.41)$ by paired t-tests. Five right-sided clavicles received the plateconstruct and 3 right-sided clavicles received the pin-construct; there was no significant difference in clavicle-laterality versus construct-type $(P=0.48)$ by chi-squared test.

Loads were measured for serial displacements for both constructs. Table 2 summarizes the data. For all displacements, the plate constructs had lower mean load. There was a significant difference between plate versus pin constructs for displacements of $5 \mathrm{~mm}(P=0.001$; Cohen's $\mathrm{d}=$ 1.49)), $7.5 \mathrm{~mm}(P=0.011$; Cohen's $\mathrm{d}=1.06)$, and $10 \mathrm{~mm}$ $(P=0.026$; Cohen's $\mathrm{d}=0.84)$ by paired t-tests with Bonferroni multi-test correction (corrected alpha $=0.029$ ). The use of Sidak multitest correction or Wilcoxon signedrank tests did not change the significance at any displacement.

Displacements were measured for several loads for both constructs. Table 3 summarizes the data. For all loads, the plate constructs had lower mean displacement. There was a significant difference between plate versus pin constructs for loads of $180 \mathrm{~N}(P=0.001$; Cohen's $d=1.85)$, 360N $(P=0.033$; Cohen's $d=1.39), 540 \mathrm{~N}(P=0.003$; Cohen's d = 0.73) and 720N $(P=0.018$; Cohen's d = 0.72) by paired t-tests with Bonferroni multi-test correction (corrected alpha $=0.027)$. At loads of higher than $540 \mathrm{~N}$, half or more of all constructs had failed. There was no significant difference at $900 \mathrm{~N}(P=0.44$ for $\mathrm{N}=2$ pairs $)$, and there were no testable data pairs at $1080 \mathrm{~N}$. The use of Sidak multi-test correction or Wilcoxon signed-rank tests did not change the significance at any load.

The experiment was designed using statistical power analysis to choose eight cadaver pairs. The power of paired ttests is 0.81 for $\mathrm{N}=8$ by Monte Carlo simulation of 2000 pseudorandom variates from a joint normal distribution with a large effect size (Cohen's $\mathrm{d}=0.8$ ).

\section{Discussion}

The main finding of the present study is that plate constructs show less displacement at fixed loads and greater loads at fixed displacements over a broad range of loads and displacements with cyclic four-point bending. The clinical relevance is that plate fixation may provide a stronger construct for early rehabilitation protocols that focus on repetitive movements in the early pre-operative period.

During a midshaft clavicle fracture, the anterosuperior surface experiences tensile forces whereas the posteroinferior surface experiences compressive forces [7]. Proubasta et al. compared a 6-hole $3.5 \mathrm{~mm}$ dynamic compression plate to a $4.5 \mathrm{~mm}$ intramedullary Herbert screw [6]. They concluded that there was no difference in strength when constructs were non-cyclically loaded in a three-point bend with the load sequentially increased to failure. Harnroongroj et al. argued that superior plating is stronger than anterior plating for transverse clavicular fractures without a cortical defect [7]. Iannotti et al. tested osteotomized and plated clavicles in compression and torsion using superior versus anterior plating with $3.5 \mathrm{~mm}$ reconstruction plates, $3.5 \mathrm{~mm}$ limited contact dynamic compression plates, and $2.7 \mathrm{~mm}$ dynamic compression plates [8]. They concluded that superior plating with $3.5 \mathrm{~mm}$ limited contact dynamic compression plates provided the best stiffness, rigidity, and strength.

Table I: Summary of clavicle and test characteristics.

\begin{tabular}{|c|c|c|c|c|c|c|c|}
\hline $\begin{array}{l}\text { Clavicle } \\
\text { Pair }\end{array}$ & $\begin{array}{l}\text { Plate Size } \\
\quad(\mathrm{mm})\end{array}$ & $\begin{array}{l}\text { Pin Size } \\
(\mathrm{cm})\end{array}$ & $\begin{array}{l}\text { Plate/Pin } \\
\text { Side }\end{array}$ & $\begin{array}{l}\text { Length } \\
(\mathrm{mm})\end{array}$ & $\begin{array}{l}\text { Diameter } \\
(\mathrm{mm})\end{array}$ & $\begin{array}{l}\text { Inner Point } \\
(\mathrm{mm})\end{array}$ & $\begin{array}{l}\text { Outer Point } \\
(\mathrm{mm})\end{array}$ \\
\hline 1 & 3.5 & 3.8 & $R / L$ & 147.5 & 13.0 & 35.5 & 105.0 \\
\hline 2 & 3.5 & 4.5 & $L / R$ & 153.0 & 16.0 & 36.0 & 109.5 \\
\hline 3 & 3.5 & 3.8 & $R / L$ & | 49.5 & 11.5 & 35.5 & 106.5 \\
\hline 4 & 3.5 & 3.8 & $R / L$ & 155.0 & 13.0 & 40.0 & 112.0 \\
\hline 5 & 3.5 & 4.5 & $R / L$ & 175.0 & 15.0 & 37.0 & 123.0 \\
\hline 6 & 3.5 & 4.5 & $L / R$ & 164.0 & 16.0 & 37.0 & 116.0 \\
\hline 7 & 3.5 & 4.5 & $R / L$ & 152.0 & 14.0 & 37.0 & 113.0 \\
\hline 8 & 3.5 & 4.5 & $L / R$ & 165.0 & 16.0 & 37.0 & 113.0 \\
\hline
\end{tabular}

Clavicle length, diameter, inner arm position, and outer arm position are averages of two matched clavicles. 
Table 2: Loads for plate versus pin constructs at displacements of $5 \mathrm{~mm}, 7.5 \mathrm{~mm}$ and $10 \mathrm{~mm}$.

\begin{tabular}{|c|c|c|c|c|c|c|}
\hline $\begin{array}{l}\text { Clavicle } \\
\text { Pair }\end{array}$ & $\begin{array}{l}\text { Load at } 5 \mathrm{~mm} \\
\text { for plate }(\mathrm{N})\end{array}$ & $\begin{array}{l}\text { Load at } 5 \mathrm{~mm} \\
\text { for pin }(\mathrm{N})\end{array}$ & $\begin{array}{l}\text { Load at } 7.5 \mathrm{~mm} \\
\text { for plate }(\mathrm{N})\end{array}$ & $\begin{array}{l}\text { Load at } 7.5 \mathrm{~mm} \\
\quad \text { for pin }(\mathrm{N})\end{array}$ & $\begin{array}{l}\text { Load at } 10 \mathrm{~mm} \\
\text { for plate }(\mathrm{N})\end{array}$ & $\begin{array}{l}\text { Load at } 10 \mathrm{~mm} \\
\quad \text { for pin }(\mathrm{N})\end{array}$ \\
\hline I & 720 & 540 & 1080 & 900 & 1080 & 1080 \\
\hline 2 & 540 & 360 & 720 & 360 & 720 & 360 \\
\hline 3 & 720 & 540 & 720 & 720 & 720 & 720 \\
\hline 4 & 720 & 360 & 720 & 360 & 720 & 540 \\
\hline 5 & 720 & 540 & 900 & 720 & 900 & 900 \\
\hline 6 & 720 & 540 & 720 & 720 & 720 & 720 \\
\hline 7 & 540 & 360 & 540 & 360 & 540 & 360 \\
\hline 8 & 900 & 360 & $>1080$ & 720 & $>1080$ & 900 \\
\hline
\end{tabular}

Values are in Newtons $(N)$. Differences are significant at $5 \mathrm{~mm}(p=0.00 \mathrm{I}), 7.5 \mathrm{~mm}(p=0.01 \mathrm{I})$, and $10 \mathrm{~mm}(p=0.026)$ by paired t-tests.

The present study focused on loosening at the boneimplant interface during cyclic bending as a putative mode of failure. Mechanical properties in static compression may affect re-injury due to an axial loading similar to a primary injury pattern. However, cyclic loading in a bending mode likely contributes to construct failure in the setting of early functional mobilization. Loosening at the bone-implant interface, fatigue failure, and broken hardware are clinical anecdotes shared by surgeons caring for patients with these injuries. In addition, repetitive bending versus repetitive torsion is more likely to be experienced in the immediate post-operative period ( 1 to 2 months) with a typical shoulder rehabilitation protocol focused on repetitive movements that avoid the extremes of motion, since torsional forces are increased at extreme forward flexion for example. The present study used load versus displacement as measures of construct integrity. In this testing context, stiffness need not be calculated from the stress strain curve, since neither linear elastic nor linear viscoelastic behavior is expected. Instead, a pattern of progressive construct failure is expected. In the present study, simple comparisons of displacement versus load and load versus displacement are reasonable surrogate measurements for a complex behavior.
There is limited clinical research directly comparing plating to intramedullary fixation for acute fractures of the clavicle. However, a study by $\mathrm{Wu}$ et al. retrospectively examined plating vs. intramedullary nailing for the treatment of clavicular nonunion [5]. The study showed an $18.2 \%$ nonunion rate with plating compared with $11.1 \%$ for nailing, the difference being attributed to the nail's resistance to compressive stresses. The authors concluded that plating provides better rotational stability, but this was not critical if the post-operative protocol limits forward flexion to 90 degrees for 1 to 2 months post-operatively. Several other studies have found intramedullary pinning to be at least equally effective as plating, especially for the treatment of nonunion, though without direct comparison $[9,10]$.

Midshaft clavicle fractures are common, and conservative management results in approximately 5\% nonunion rate [11]. While non-operative management remains the mainstay of treatment for most midshaft clavicle fractures, the indications for surgery may be expanding. A recent multicenter randomized controlled trial comparing plate fixation to conservative management demonstrated improved functional outcome and lower rates of nonunion and malunion at one year [12].

Table 3: Displacements for plate versus pin constructs at various loads after all 3000 cycles have elapsed for the load.

\begin{tabular}{|c|c|c|c|c|c|c|c|c|}
\hline $\begin{array}{c}\text { Clavicle } \\
\text { Pair }\end{array}$ & $\begin{array}{l}\text { Displacement } \\
\text { at } 180 \mathrm{~N} \text { for } \\
\text { plate }\end{array}$ & $\begin{array}{l}\text { Displacement } \\
\text { at I } 80 \mathrm{~N} \text { for } \\
\text { pin }\end{array}$ & $\begin{array}{c}\text { Displacement } \\
\text { at } 360 \mathrm{~N} \text { for } \\
\text { plate }\end{array}$ & $\begin{array}{l}\text { Displacement } \\
\text { forat } 360 \mathrm{~N} \\
\text { pin }\end{array}$ & $\begin{array}{l}\text { Displacement } \\
\text { at } 540 \mathrm{~N} \text { for } \\
\text { plate }\end{array}$ & $\begin{array}{c}\text { Displacement } \\
\text { at } 540 \mathrm{~N} \text { for } \\
\text { pin }\end{array}$ & $\begin{array}{l}\text { Displacement } \\
\text { at } 720 \mathrm{~N} \text { for } \\
\text { plate }\end{array}$ & $\begin{array}{c}\text { Displacement } \\
\text { at } 720 \mathrm{~N} \text { for } \\
\text { pin }\end{array}$ \\
\hline I & 1.18 & 1.57 & 1.89 & 2.35 & 3.00 & 5.30 & 5.58 & 6.98 \\
\hline 2 & 1.58 & 2.14 & 3.73 & -- & 6.32 & -- & 8.73 & -- \\
\hline 3 & 1.06 & 2.15 & 1.84 & 3.53 & 3.25 & 4.94 & -- & -- \\
\hline 4 & 1.70 & 2.80 & 2.18 & 8.97 & 3.80 & -- & -- & -- \\
\hline 5 & 0.93 & 1.38 & 1.95 & 3.54 & 3.66 & 5.23 & 5.76 & 7.86 \\
\hline 6 & 0.84 & 2.38 & 1.73 & 4.75 & 3.34 & 6.90 & 10.7 & 12.7 \\
\hline 7 & 1.20 & 1.65 & 2.52 & -- & 9.40 & -- & -- & -- \\
\hline 8 & 1.72 & 2.50 & 2.88 & 5.14 & 3.60 & 6.48 & 4.35 & 8.04 \\
\hline
\end{tabular}

Values are in millimeters. Differences are significant at I80N $(p=0.00 \mathrm{I}), 360 \mathrm{~N}(\mathrm{p}=0.033), 540 \mathrm{~N}(\mathrm{p}=0.003)$ and $720 \mathrm{~N}(\mathrm{p}=0.0 \mathrm{I} 8)$ by paired ttests. At loads of higher than $720 \mathrm{~N}$, over half of constructs had failed. 


\section{Conclusion}

For the fixation of midshaft clavicle fractures, plate constructs show less displacement at fixed loads and greater load at fixed displacements over a broad range of loads and displacements with cyclic four-point bending.

\section{Competing interests}

The authors declare that they have no competing interests. No author has contractual obligations, consultant agreements, is a stockholder, or has other competing interests regarding ACE/Depuy, Warsaw, IN, USA which provided support.

\section{Authors' contributions}

SRG contributed to analysis and interpretation of data, and to drafting the manuscript. JAO contributed to conception and design, to acquisition of data, and to drafting the manuscript. EIF contributed to conception and design, and to drafting the manuscript. MDM contributed to conception and design, to analysis and interpretation of data, and to revising the manuscript critically for important intellectual content. All authors have given final approval of the version to be published.

\section{Acknowledgements}

The authors acknowledge ACE/Depuy, Warsaw, IN, USA which provided orthopaedic hardware and cadaveric specimens, but no cash, travel, salary, or other equipment support.

\section{References}

I. Robinson CM: Fractures of the clavicle in the adult. Epidemiology and classification. J Bone Joint Surg Br 1998, 80(3):476-484.

2. Stanley D, Trowbridge EA, Norris SH: The mechanism of clavicular fracture. A clinical and biomechanical analysis. J Bone Joint Surg Br 1988, 70(3):46I-464.

3. Hill JM, McGuire MH, Crosby LA: Closed treatment of displaced middle-third fractures of the clavicle gives poor results. J Bone Joint Surg Br 1997, 79(4):537-539.

4. Denard PJ, Koval KJ, Cantu RV, Weinstein JN: Management of midshaft clavicle fractures in adults. Am J Orthop 2005, 34(I I):527-536.

5. Wu CC, Shih CH, Chen WJ, Tai CL: Treatment of clavicular aseptic nonunion: comparison of plating and intramedullary nailing techniques. J Trauma 1998, 45(3):5 I2-516.

6. Proubasta IR, Itarte JP, Caceres EP, Llusa MP, Gil JM, Planell JA, Ginebra MP: Biomechanical evaluation of fixation of clavicular fractures. J South Orthop Assoc 2002, I I (3): | 48- I 52.

7. Harnroongroj T, Vanadurongwan V: Biomechanical aspects of plating osteosynthesis of transverse clavicular fracture with and without inferior cortical defect. Clin Biomech (Bristol, Avon) I996, I I(5):290-294.

8. lannotti MR, Crosby LA, Stafford P, Grayson G, Goulet R: Effects of plate location and selection on the stability of midshaft clavicle osteotomies: a biomechanical study. J Shoulder Elbow Surg 2002, I I(5):457-462.

9. Capicotto PN, Heiple KG, Wilbur JH: Midshaft clavicle nonunions treated with intramedullary Steinman pin fixation and onlay bone graft. J Orthop Trauma 1994, 8(2):88-93.

10. Enneking T], Hartlief MT, Fontijne WP: Rushpin fixation for midshaft clavicular nonunions: good results in 13/14 cases. Acta Orthop Scand 1999, 70(5):514-516.

II. Nowak J, Mallmin H, Larsson S: The aetiology and epidemiology of clavicular fractures. A prospective study during a two-year period in Uppsala, Sweden. Injury 2000, 3 I(5):353-358.

12. Canadian: Nonoperative treatment compared with plate fixation of displaced midshaft clavicular fractures. A multi- center, randomized clinical trial. I Bone Joint Surg Am 2007, 89(I): 1 - 10 .
Publish with Biomed Central and every scientist can read your work free of charge

"BioMed Central will be the most significant development for disseminating the results of biomedical research in our lifetime. "

Sir Paul Nurse, Cancer Research UK

Your research papers will be:

- available free of charge to the entire biomedical community

- peer reviewed and published immediately upon acceptance

- cited in PubMed and archived on PubMed Central

- yours - you keep the copyright

Submit your manuscript here:

http://www.biomedcentral.com/info/publishing_adv.asp
BioMedcentral 